Running head: Negotiating Multiplicity

Negotiating Multiplicity:

Adaptive Asymmetries Within Second Generation Turks' 'Society Of Mind'

Emma-Louise Aveling ${ }^{1}$

Department of Social and Developmental Psychology

School of Social and Political Sciences

University of Cambridge

Free School Lane

Cambridge CB2 3RQ, UK

Tel: + $44(0) 1223338067$

Fax: + $44(0) 1223334550$

Email: ela29@cam.ac.uk

\title{
Alex Gillespie
}

Department of Psychology

University of Stirling

Stirling FK9 4LA

UK

\footnotetext{
${ }^{1}$ Author for correspondence
} 
Negotiating Multiplicity:

Adaptive Asymmetries Within Second Generation Turks 'Society Of Mind’

\begin{abstract}
If identities are socially produced, what happens when individuals grow up participating in divergent or conflicting social contexts? This paper reports upon research with second generation Turkish adolescents in London. Using the concept of the dialogical self, the research examines the dialogical structure of these young Turks' selves. The analysis is Bakhtinian and seeks to identify the different discourses through which these young Turks talk about themselves. Three distinct discourses, or I-positions, are identified. These are then related to the sociocultural context within which these youth live, and specific attention is given to the constraints upon these youth in expressing aspects of their identity. We demonstrate that the asymmetries and tensions within these adolescents' dialogical selves are adaptive to the fractured and asymmetrical social contexts in which they are embedded.
\end{abstract}

Keywords: Dialogism, self, Bakhtin, identity, adolescents, Turks 
Negotiating Multiplicity:

Adaptive Asymmetries Within Second Generation Turks 'Society Of Mind’

The concept of the Dialogical Self is ideally suited to analysing identity in the current context of globalisation (Hermans \& Dimaggio, 2007). It has long been recognised that the self is forged in cultural and community contexts (James, 1890). While all adolescents in late modernity must negotiate a heterogeneous and fragmented society (Rappoport, Baumgarden \& Boone, 1999), for second generation ethnic minorities, socialised into both the culture of their parents and the host culture, the existential drama is even greater (Parker, 1995). The present research focuses upon identity work and dialogical positioning amongst young Turks ${ }^{2}$ growing up in London. Specifically, our aim is to use the concept of the dialogical self to pursue the fragmented and asymmetrical sociocultural context experienced by these second generation immigrants into the micro-dynamics of identity.

\section{Identity And Globalisation}

The rapid pace of change in contemporary societies is evident in the increasing “moving and mixing”, collapsing and coalescing of cultures (Hermans \& Kempen, 1998, p. 1117). Globalised communication technologies, cheaper travel, increased transnational migration and the creation of diasporic communities, and the expansion of capitalist commodity and culture production have transformed everyday life across the globe (Giddens, 1991). This sociocultural flux has led to new forms of cultural identity, especially the construction of 'hybridised’ identities (Hermans \& Kempen, 1998). Much research has described the agency and creativity of second generation adolescents in drawing on multiple cultural resources to construct novel, ‘in-between’ identities (Back 1996; Gervais \&

\footnotetext{
${ }^{2}$ The Turkish-speaking population consists of Turks, Kurds and Turkish-Cypriots. Participants referred to themselves under the general category of 'Turks', thus I shall follow their terminology. This does not include young Kurds, who constitute a more distinctive group within the Turkish-speaking community (see Enneli, Modood \& Bradley, 2005).
} 
Jovchelovitch, 1998). However, the notion of hybridised identities should not be taken to imply an integrated developmental end-point. Rather it characterises a complex of multiple, shifting identities and an on-going process of negotiation as different aspects mutually define and redefine each other (Howarth, 2002; Bhatia \& Ram, 2001; da Cunha, 1995). Moreover, these identities, embedded in multiple, overlapping cultural territories are contextual and contingent (Baumann, 1996; Nagel, 1996). Thus for the British-Sikh teenagers in K. Hall’s (1995, p. 254) study, there is a "time to act English" and a “time to act Indian”, as well as a time to "play with the identities in between”. This highlights the importance of attention to the sociocultural context, including what kind of "time” the research setting represents and how the participants are engaging with that context.

Despite the evidence of creativity and novelty in the emergence of ethnic identities, identities are not freely constructed. Rather, identity construction involves a negotiation between internal identifications and external ascriptions (Nagel, 1996). As Bhatia (2002) argues, these dialogues are always situated in a macro context influenced by historical and political issues of racism, gender, imperialism and power. For example, the power of new racist discourses based upon cultural purity has been revealed in Enneli, Modood \& Bradley (2005, p. 38) finding that young Turks in the UK felt that "British" identity, in its "wider, ethnic or cultural meaning” could only be claimed by white English people.

An additional identity constraint is provided by the stories, legacies and immigration heritage within the given ethnic group (Bhatia \& Ram, 2001; Bhatia, 2002). For example, Mandel (1995) shows that discourses of return or repatriation constitute the 'master narrative' for the Turkish diaspora in Germany; yet for the second generation, some of whom have never been to Turkey, this discourse is replete with paradoxes and contradictions. Similarly, K. Hall (1995) has examined the constraining forces of cultural conservatism within the British-Sikh community. 
The children of immigrants therefore must find their positions within a particularly taut tangle of contradictory demands and discourses from both their ethnic community and the wider society. The aim of the present research is to provide a dialogical analysis of the identity construction of second generation Turkish immigrants in London, an 'invisible minority' in both youth and ethnicity research (Enneli, Modood \& Bradley, 2005). Based on previous research, we attempt to articulate both the constraints upon and the creativity within their identity construction. Often culture and agency are separated and opposed. In contrast, our approach conceives of culture as a semiotic system through which individuals think and act (Valsiner, 2002; Gillespie, 2006a). Yet, for ethnic minority youths in particular, such cultural contexts are structured by asymmetries of power. The process of identity construction therefore entails not only an accommodation of the potential cultural 'pushes and pulls', but also adapting to the constraints imposed by such asymmetries.

\section{The Dialogical Self}

The concept of the dialogical self (Hermans, 1996, 2001a, 2001b; Hermans, Kempen, \& vanLoon, 1992) can be used to elucidate identity dynamics within a heterogeneous sociocultural context. The self is depicted as a multiplicity of I-positions representing a “society of mind” (Hermans 2002, p. 147 ). Each of these I-positions stands in some relation to the social world, such that the "growing complexity of the world goes hand in hand with the growing complexity of the self” (Hermans, 2001b, p. 361).

The concept of I-positions goes back to James’ (1890) distinction between the 'I' and the 'Me'. The 'I' is the position from which someone acts or speaks, it is self as subject. While the 'Me', on the other hand, is self as object, or self as known to self. To describe the self as a dynamic multiplicity of relatively autonomous I-positions is to 
recognise that there are many distinct discursive and action positions that an individual can take up. This makes possible internal dialogue as the I-positions within this polyphonic self can "agree, disagree, misunderstand, oppose, contradict, question, challenge and even ridicule the I in another position” (Hermans, 2001a, p. 249).

Where does this heterogeneity come from? The words we use and the discourses we take up are not only our own (Bakhtin, 1981). The words one uses are also always another's words: we both shape and are shaped by the words and the narrative traditions in which they are embedded (Shotter, 1993). If the individual lives in society with competing discourses, then in taking up those conflicting discourses, so we will find the conflict within the individual. Equally, if the individual inhabits two quite different social contexts, each with its own discourse, so within the individual we will find these two discourses. The study of the dialogical self is the examination of these social discourses within the individual.

Crucially, the macro-context in which the dialogical self is embedded is characterised by patterns of dominance and asymmetries in social power. Due to such differences, some groups (e.g. English people) have more opportunity to be heard than others (e.g. ethnic minorities). The discourses of dominant groups thus constrain the subject positions available to be occupied by less powerful others. Consequently, power asymmetries within the sociocultural environment become reflected within the 'society of mind', organising, colouring and constraining the meaning system that emerges (Valsiner, 2002).

The following research uses the concept of the dialogical self to analyse the Ipositions occupied by second generation Turks, the discourses through which they speak, and the origins of these discourses in their social world, thus providing a window into their asymmetrical sociocultural context. 


\section{Research Context: Turkish Adolescents in London}

The participants in this study (five boys, five girls, aged 14-18 years) were all students at a Turkish Supplementary School in North London. All were born and brought up in the England. Nine participants have Turkish Cypriot parents; one has one Turkish and one Turkish Cypriot parent. All the students had been at the school between 2.5 and 10 years. The school, which operates every Saturday is run by parents and professionals in the Turkish and Turkish Cypriot diaspora, to teach second- and thirdgeneration Turks and Turkish Cypriots about their heritage, including Turkish language, music and dance.

This Turkish school is a part of a large, vibrant and independent Turkish community. The tight-knit nature of this community is evident in the fact that half of the participants in this sample were related to members of staff. The students in this sample had also known each other for a number of years, and said that, although it had been their parents who encouraged them to come initially, they also saw it as an important opportunity to socialise with their friends from the Turkish community.

The main method of data generation was interviews (10 individual and 2 group) conducted by the first author. All of the interviews took place during the Turkish Supplementary School hours, in an unused classroom, and lasted between 55-65 minutes each (11 hours 26 minutes in total). Students were first interviewed individually, and then in one of the two focus groups.

The individual interviews covered participants’ experiences at mainstream school and Turkish school, descriptions of their families and friendships, social/leisure activities, Turkish language facility and use, perceptions of the Turkish community and their place within it and their hopes and aspirations for the future. Following Kvale (1996), the focus groups were a form of 're-interview', which allows the researcher to 
reflect back emerging ideas and assess how common salient understandings are to the group. Thus the topics in the group interviews overlapped with topics from the individual interviews.

Participant observation was also used. This included background reading of relevant books, newspapers and internet sites, observation of school activities, and informal discussions with students. Combined with interviews with two staff members, this method provided insight into the nature of the discourses surrounding the participants (Marshall \& Rossman, 1995). During two months of weekly visits to the school, the first author was able to observe assemblies, classes, special events (e.g. Turkish festival celebrations) and interactions between staff, parents and students.

\section{Analysis: From The ‘Society Of Mind’ To Society}

Coding the data aimed to identify the I-positions from which participants spoke, the relation between these I-positions and the sociocultural context, and analyse conflicts and asymmetries within the dialogical self in terms of conflicts and asymmetries within that sociocultural context. To these ends, the coding and analysis proceeded in three phases.

The first phase of coding used in vivo codes (Strauss, 1987) to identify the main Ipositions. These codes included ethnic self-identifications and ethnic identifications ascribed by others. These were supplemented by a 'hybridised' code, derived from the literature on novel identities. Application of codes moved beyond self/other identifications, to attitudes, values, aspirations and reported practices that constituted expressions of those identity positions. It was an iterative process, whereby interviews were compared and contrasted and initial codes refined over several cycles as cultural I-positions emerged and code boundaries became more distinct.

The second phase of coding asked, “who is doing the talking?” (Wertsch, 1991, p. 63) in order to identify the social origin of I-positions, or voices, in participants' utterances. 
Following previous research (Gillespie, 2006a, 2006b, 2007; Gillespie, Cornish, Aveling \& Zittoun, 2008), this analysis coded reported speech and echoes. Reported speech refers to utterances which are attributed to specific others (e.g., parents, peers, teachers etc.) and generalised others (e.g., "the Turkish community”). Echoes are utterances which are not attributed to others, but which nonetheless seem to have a distinct social origin beyond the speaker. The main aim of this phase was to systematically relate the I-positions identified in phase one, with the sociocultural context and discourses.

Finally, the analysis focused on shifts between I-positions. This process was supported by a cycle of coding for contradictions within each interview and between individuals' responses in the interview and focus group. The focus was upon dialogical tensions between I-positions and how these relate to the sociocultural context.

The following presentation of the analysis details the three identified I-positions: I-as-Turkish, I-as-Ethnic-Other, and I-as-a-young-Turk-in-England. For each of these Ipositions our presentation describes the I-position, analyses the social origin of the Iposition, and then proceeds to analyse the dialogical tensions relating to that I-position. Towards the end of our analysis we try to relate these tensions to the sociocultural context and existent power asymmetries.

\section{I-As-Turkish}

Unlike many studies of second-generation youth (e.g. Modood et al., 1997), not one participant in this study used a hyphenated identity label, such as British-Turkish, in their initial self-presentations. Without being asked directly, all participants described themselves as “Turkish”. Only three, in further elaborating, explained that they were “probably” half and half (English and Turkish), though one qualified this with "but I think you've gotta be a bit more of one than the other” (i.e. more Turkish). 
For all participants, I-as-Turkish was the dominant voice. Even for those who feel they are partly English, their use of language (e.g. possessive pronouns) reflects the dominance of I-as-Turkish, and the difference felt between 'us' (Turkish) and 'them' (those outside the Turkish community). Yusuf articulates the centrality of the Turkish Iposition:

I don't want to forget that I'm Turkish- I wouldn't want to ever forget that- I mean its not really big- but it's a good part of my life -cos everything revolves around me to do with Turkish.

This Turkish identity was also associated with a great deal of pride, which was frequently expressed without direct questioning. For example, one participant explained that he pronounces his name the Turkish way because:

Ahmet: You gotta show who you are [...]

Emma: And who are you?

Ahmet: Turkish-Cypriot and proud to say it, yeah

Such claims of a Turkish identity must be understood contextually. Arguably, being interviewed by a white British woman, who had asked to speak to second generation Turkish adolescents within the school, may have produced a context in which these adolescents felt an expectation to assert their Turkish identity. However, this does not mean that such identity positioning may be false. Such an identity positioning is as 'real' as the situation which produced it. Moreover, identities are not completely context bound, and there are demands for consistency across contexts. For example, all participants were wearing "the moon and star" (a pendant symbolising the Turkish flag) because "its basically saying [...] I'm proud that I am a Turk", and it is saying this in all contexts.

For all participants knowing their Turkish heritage - their culture and their language - is an important aspect of the Turkish I-position, as reflected in their tendency to exaggerate their use of Turkish amongst friends. Indeed, all participants suggested 
that not knowing one’s language and culture could compromise claims to a Turkish identity, as Fatma explained:

Emma: And so does it make any difference if they [other young Turks who aren't taught about it] don't know about their culture and you do?

Fatma: Well- me as a person who loves my culture- I think it matters because if you define yourself as Turkish then in my opinion you should know your languageyou should know your traditions- you should know your customs

For about a third of the group, not knowing the language and culture deserves criticism, even condemnation: such people do not deserve to be considered “True Turks”. Who is doing the talking?

If we ask 'who is doing the talking?', echoes of the voice of the Turkish community can be heard. Often the voice echoes generalised feelings within the Turkish community, about the need to be proud of Turkish culture and identity. Consider, for example, Atatürk’s 'pledge’, 'Andimiz', , which is recited every Saturday morning in assembly at the Turkish school. Many of the participants made reference to the pledge.

Mehmet: Its like a speech said by Atatürk which was, it just signifies that you are Turkish- what you should- its just like a basic law Emma: And what does that mean [..] in the speech when they are talking about being Turkish, what does that mean?

Mehmet: Just like basically saying you have got to do anything you can to preserve Turkey- or Cyprus whatever and like at the end they say 'Ne mutlu turk'um diyene!'- that's like- 'forever be happy that you're Turkish'- so it just signifies that you should be proud of who you are

In Mehmet's utterances we can hear the voice of Atatürk and a popular saying, and thus we can see the macro discourses manifesting within Mehmet's dialogical self. As with all of the other participants, the collective voice of Turkish culture interpolates Mehmet's dialogical self.

There are also many references to specific voices, especially the voice of parents. For example, some participants ventriloquate the voice of their parents and teachers that they are living "in a foreign country" - "foreign” because "who you are” is

\footnotetext{
${ }^{3}$ The recital of his pledge entails pledging to be hard-working, honest, respectful to one's elders and protect those younger, and to be proud to be a Turk.
} 
“in your blood”. These voices appear to encourage their children to associate awareness of their cultural heritage and pride in the Turkish identity with family loyalty. The power of this discourse was particularly evident with regard to marriage. All participants said that their parents would prefer, in some cases insist, that they married within the Turkish community:

Emma: Do you think about getting married, or having a family?

Ayse: [...] If I marry a person he would have to be a Turkish Cypriot- not only for me but- for my parents as well -because they told me- 'if you bring someone from a different culture then - you forget me- you'll forget your family'

Here one can hear the voice of Ayse's parents, equating marriage outside the community with neglecting both her heritage and her family, within Ayse’s dialogical self.

This emphasis on the link between heritage and Turkish identity is implicitly dichotomising, and perhaps underlies some of the tendency to choose to emphasise a 'pure Turk’ identity, rather than present themselves as, for example, British-Turkish. As Ahmet said, “there’s not one drop of blood in me that’s English so you know - I can’t be British”. That is, reflecting the voices of the Turkish community, these young people would find if difficult to claim to be both Turkish and British.

\section{Dialogical tensions}

Besides asking 'who is doing the talking?' a dialogical approach also needs to ask the question, 'who is being talked to?' Every utterance is oriented to an audience, makes presuppositions about the audience, and aims to have some effect upon the audience. So, in the above cases when we hear the voice of the I-as-Turkish arise, what are these utterances doing? Consider again Ahmet, who says that he is "Turkish-Cypriot and proud to say it, yeah”. Why does Ahmet feel the need to say that he is proud, and then affirm this with a "yeah”. Pure pride needs no self-assertion. Equally, consider Yusuf who says “I don’t want to forget that I’m Turkish”. Such an utterance implies 
that the alternative exists as a possibility, yet the voice of the Turkish community at times appears to deny this possibility. Indeed it is this possibility which motivates these utterances. So here, then, in these seemingly simple assertions of I-as-Turkish, we find faint traces of a dialogical tension, which we will examine in greater detail later.

\section{I-As-Ethnic-Other}

Another I-position to emerge was the I-as-Ethnic-Other. This position is less dominant than I-as-Turkish, but nonetheless has a distinctive voice, which was particularly prominent when talking about their mainstream school life. Significantly, implicit in this representation is a denial of access to an English identity from the more powerful social group - “white English people”. As Ahmet put it, "ethnic is not being English- innit?”, an understanding reflected in their own descriptions of who qualifies to be English - people with white skin and English parents. Moreover, the dichotomising discourse of English-Ethnic mutual exclusivity echoes their own I-as-Turkish exclusiveness.

K. Hall (1995) argues that this rationalisation leads to the collective marginalisation of ethnic minority students in mainstream schools. While all the participants at times spoke from this position: some merely acknowledged this representation; for others, they “don’t fit in here”; a small minority felt they had experienced outright discrimination or racism in mainstream school. Yet there was also a more subtle sense of marginalisation, whereby many felt that important skills were not recognised by the mainstream school because they were 'ethnic' e.g. their Turkish A level qualification.

Who is doing the talking?

While participants may speak from the I-as-Ethnic-Other position, when we ask 'who is doing the talking?', we see that this position emerges from a particular aspect of 
the way the participants find themselves represented by the "majority white" within mainstream British society. “The ethnic minority” Hassan said, “that’s what they call us” - "they” being the “majority white” mainstream school peers and, for some, teachers. Discourses surrounding ethnic minorities prevalent throughout multicultural London are also echoed in participants’ utterances. For example, participants described how ethnicity monitoring forms often force them to choose 'other' or even 'white other', even though for many, their position on the white/non-white divide is ambiguous (Howarth, under review). Here we see the institutionalised voice of the hegemonic English culture positioning and classifying these young Turks.

\section{Dialogical tensions}

This positioning by others as "ethnic" enters into the dialogical self of these youth, providing them with a new facet of their identity and coming into conflict with existing facets. While unable to deny that they fall in to the "ethnic" category, all participants express some resistance to this alienating representation. Thus the dialogical tension seems to arise mainly in the way that the I-as-Ethnic-Other works to exclude these youth from an English identity. Their resistance is complex and is most clearly revealed when participants claim to be "half and half”. The question is, at what point does one cease to be "ethnic" and become British? How can one make this transition if one is being excluded from the British identity? These tensions become explicit when we consider the hybridised I-as-a-young-Turk-in-England position.

$$
\text { I-As-A-Young-Turk-In-England }
$$

The participants feel alienated from a British identity position, and feel the discourse of ethic minorities to be foreign. Yet we have also seen that they are not simply occupying a Turkish identity position. While the voice of parents is strong, these youth do not align themselves completely with these voices. A close analysis of identity 
positioning reveals yet another identity position which we call I-as-a-young-Turk-inEngland. As this title suggests, this I-position is hybrid, but it is not yet reflexive. This is not a position that is explicitly claimed; rather it is a position from which these youth speak and reflects an attempt to negotiate the tension between the demands of their home community and the wider society.

Most participants agreed they were British in the narrow, technical sense of being born here and having a British passport. However, in contrast to the majority of Asians and Caribbeans (Modood et al., 1997), the majority completely rejected an English or British identity in the "wider, cultural or ethnic meaning” (Enneli, Modood \& Bradley 2005, p. 38). For example:

Hatice: Turkish Cypriot I would class myself as [...] Yes, that fits me. Emma: Right. Would you say you were also British or English in any way? Hatice: Definitely not [laughs] No. I've got the passport I live in a country but I would not class myself as British [...] I wouldn't say I am British because I live in the country- I speak the language but I wouldn't want to be [...] I've got the passport- I live in the country -but [...] I would never define myself as British

However, amongst the group there were three who acknowledged they were "probably half and half”. For example, for Zehra:

I would say I am Turkish Cypriot slash British citizen kind of thing-- I've got the Turkish Cypriot in me- but also the English cos I've grown up here and gone to English school so- yeah I've got a bit of both in me

In such utterances the hybridised I-position is most explicit, but even amongst those who rejected such hybridisation, and claimed they were not English, and didn’t “want to be”, there is also evidence of hybridisation. One illustration of this is their use of English. Yusuf, for example, said that even with friends from Turkish school he speaks mainly English because “its like- in your mind really cos you think English you're gonna speak English [...] my Turkish isn't 100\% good so- I'm more confident speaking English”. 
This represents a contradiction with subsequent denials of an 'English' identification according to their own definition of what it means to be Turkish: knowing the language is a marker of a particular cultural identity, thus there is some tension. For example, Hatice points out explicitly that this definition includes English identifications:

In my opinion, if you class yourself as something, like if you class yourself as English you should know the English culture, you should know the language Yet Hatice would “never” define herself as English. In this sense, this hybrid position is more of an enacted I-position than a reflexive 'me'. The 'me' is very much 'Turkish', but the actions, the I-positions from which they act are hybridic and contain traces of a more British I-position.

Another illustration is the fact that England, not Cyprus, is where they felt most at home and where they saw their future. This sense of belonging in England included frequent references to the ethnic diversity of their friendship groups, in contrast to the more segregated friendship patterns of their parents' generation. Consequently Hatice (who would "never” define herself as British) says, "that's why I would probably be more British than anyone [in my family]”.

\section{Dialogical tensions}

While few participants explicitly claim a hybrid identity such as British-Turkish (or vice versa), the enacted hybridised identity position of a young-Turk-in-England nonetheless creates dialogical tensions within the young Turkish self. The expression of this hybridised position often conflicts with the prescriptions of the Turkish voices linked to I-as-Turkish and thus contradicts their own assertions of a "True Turk" identity.

The following excerpt illustrates such internal dialogical tensions being played out in Ahmet's external dialogue. As described, all participants felt their parents would 
prefer, if not insist, they marry a Turkish/Turkish Cypriot person. Speaking from the position of I-as-Turkish, most accepted this societal prescription. Yet dialogical tensions between I-as-Turkish and a more hybridised position are evident (though at times the voices cannot be disentangled-marked thus):

Emma: And do your parents have ideas about the kind of person they would like you to marry?

Ahmet: Yeah they have! (laughing) It's been drilled in my head since I was a baby, every single day like- 'you've gotta marry a Turkish girl- you can't dishonour the family' and stuff like this but I don't really care because love only comes once in a lifetime I think-you've just got to take it, even if it means family's gotta gofamily's gotta go.

Emma: Is that what would happen if you wanted to marry some body who wasn't Turkish?

Ahmet: Definitely. But the thing- is if I liked a Greek bird then that would cause a lot of problems- and I would not blame my mum or my dad at all- whereas I think that if I married an English girl I could say you lot have got backwards views but if I married a Greek bird then I would be- no- treading in really really deep waters because my dad's like been a prisoner of war and my mum was left without a dad at the age of 8 so by that I would definitely respect that but to be honest even if there was a Greek bird and I really really did like her I think I would go with her.

Ahmet is able to give voice to the different perspectives. We hear the "True Turk", who "would not blame” his parents and "definitely respect” them, but also the hybridised identity position. Through the latter voice, he positions himself in relation to those voices (as a young person in England) outside the values of the Turkish community, saying, for example, “you lot have got backwards views”. In shifting between Ipositions and hearing himself from another position, he says "to be honest” as if recognising that is a lie. What drives Ahmet to this contradiction? Although Ahmet often affirms his I-as-Turkish position, a voice which respects prescriptions to remain loyal to the culture and values of the Turkish community, he also holds some independence and expresses views which contravene such values, specifically, a commitment to love marriage.

Thus while we see frequent and vehement self-identifications as Turkish, dialogical tensions exist in that the thoughts and actions of these youth also reveal a 
more hybridic identity, albeit one they are reluctant to acknowledge in their selfidentifications. Indeed, speaking with their Turkish voice, hybridity is "frowned on”. To understand the privileging of the Turkish voice and the defensive rejection of an English, or even hybridised, identification requires consideration of the socioculturally situated voices linked to and shaping the development of their various I-positions.

\section{Rejecting an English identity}

One reason for the overt rejection of an English identity, despite evident hybridity, can be found in the context of a fragmented multiculturalism in North London. For these participants, being British or English in Enneli, Modood \& Bradley’s (2005) “wider, cultural or ethnic sense” appears an ambiguous, if not vacuous, notion. As Hatice commented:

Emma: What does count as a British person then?

Hatice: They probably have to be, like their parents have to be born into a British family and culture, I'm not sure, I don't have any proper British friends Emma: No? even from your other school?

Hatice: No, they're all- English people have become so diverse- you can't find anyone- its like old people you can- but our age- I haven't met a proper British person in ages

This is in contrast to the very clear sense of a Turkish identity supported by the Turkish diaspora and supplementary school, which potentially offers the kind of coherent world view that, in Erikson’s (1968) view, young people need to fashion their identity. Perhaps, then, students' desire to "stay true to [their] origins- especially in London cos there's so many different origins” is, in part, a response to the experience of uncertainty precipitated by the increasing density and heterogeneity of positions and possibilities in multicultural London and an ever-more globalised world (Hermans, 2001a).

However, this is not sufficient explanation. Examining the collective voices of both the Turkish community and the wider society that populate these adolescents' 'society of mind' (Hermans, 2002) reveals two significant and mutually reinforcing 
discourses of ethnicity that shape the development of their I-positions: both work to exclude these Turks from an English I-position despite their socialisation into the multiculture of London.

First, there is the dichotomising discourse of British ethnocultural purity (cf K.Hall, 1995; Back, 1996). In being represented as ‘ethnic minorities’, or even simply 'not white', these young people are denied access to an English identity by a more powerful majority. The resulting $I$-position of $I$-as-ethnic-other would be in direct conflict with an I-as-English. For example, although Mehmet attempts to contest this denial in his interview (“well I am half English”), it is sufficiently powerful that in the focus groups he asserts “we just don’t fit in in this country”.

Second, there is the dichotomising discourse of Turkshiness which exists within the Turkish community. Within this discourse, to voice an English, or even hybridised identity, warrants social sanction as a betrayal of being a "True Turk". For example, during one focus group, two boys emphatically rejected an English identity. The third participant disagreed, but in so-doing felt he had to defend this position and his claims to a Turkish identity:

Ahmet: [..] this is my home- sorry boys but-it is [laughter in the group] [..] I mean- don't get me wrong- I'm still Turkish- d'you know what I mean- Turkish and proud of it- it don't mean that just cos- just cos- [I fit in here Mehmet: [yeah yeah- that doesn't make you a bad person just by saying that- it's just an opinion innit?

Ahmet's defensiveness, along with Mehmet's reassurance implies a danger that this treacherous utterance could make Ahmet a "bad person"- that is, someone who has forgotten their culture and "who they are”. Furthermore, in individual interviews both the other participants had previously expressed a greater sense of belonging in England (and for Mehmet, “if I look at it, I'm half and half”), yet neither felt able to acknowledge an English identification in the group situation with their Turkish peers. 
However, there is also another context in which these youth are attributed an English identity and denied a Turkish identity. This conflicting discursive context arises when these young Turks go back to Cyprus or Turkey to visit relatives. Many participants mentioned in their interviews, and everyone in the focus groups agreed that, during such visits they had experienced Turkish family calling them ‘the English'. For example:

Ayse: Yeah- they live in Cyprus- they say cos your London you're English- you just an English now

Emma: What do they mean if they say that to you?

Ayse: Well, basically, what they are trying to say is that because I am from London I'm not a Turk no more- I'm English

Emma: And how does that make you feel?

Ayse: It's really annoying

Such discursive interactions threaten their claims to I-as-Turkish - because who you are is "in your blood”. Thus this collective voice reinforces the dichotomising, mutually exclusive perception of 'English' and 'Turkish' identities, but from the opposite direction: in this case they may be denied access to a Turkish identity. Given the implicit sense of familial loyalty in assertions of the Turkish identity, this accusation may be all the more powerful. Thus what we observe in the dialogical tensions within these second generation Turkish youth is a double rejection. Instead of being positioned with identities that encompass both their family origin and their own current situation, they are forced to construct an identity in the space between being Turkish and British, yet not provided with the discursive space in which to do so.

\section{Negotiating Multiplicity}

The preceding section described the various cultural I-positions participants have marked (with personal variations). The self-constructions they present are both shaped by and a reflection of the asymmetrical power relations between different cultural voices within their 'real' environment, both as adolescents within the diaspora 
and members of an ethnic minority in Britain. Thus these second-generation adolescents are caught in a tangle of loyalties and racialising discourses, and the consequent identity struggles are manifest in complex dialogical relations between the individual and collective voices that constitute the self.

Of particular interest is the apparent contradiction between assertions of being a 'True Turk', and evidence of a more hybridized I-position than this self-narrative allows for. This contradiction is crystallized in the following rap lyric, taken from a website run by one of the participants and familiar to all of them; indeed, several of them have their photographs posted on the web page from which this rap plays.
I'm from the UK
but don't be mistaken
pass the kebab
keep your egg and bacon
see it's where you're from
not where you're at
now I'm from Cyprus
and that's a fact

Central to this narrative is the dominance of I-as-Turkish: both the rap and the web page are intended to affirm their status as 'True Turks'. The dominance of I-as-Turkish in this self-narrative is an adaptive response to the various (conflicting) ways in which they are positioned by the essentialising discourses in their sociocultural context. While admitting the technical British identity - “I’m from the UK” - it also acknowledges the prescriptions of the Turkish community in showing they have not forgotten "it's where you're from/ not where you're at”. It also represents a defence against accusations that they are English and no longer Turkish - so “don’t be mistaken”. While maintaining a positive Turkish identification, from the perspective of I-as-Ethnic-Other they invoke cultural stereotypes to accept the implicit outsider status- "pass the kebab / keep your egg and bacon”. This perhaps represents a way of reclaiming agency within the 'othered', marginalized space of being 'ethnic'. Further, this narrative allows them to 
impose clarity and boundaries on the fragmented multiculturalism of London: there may be many different origins, but "I'm from Cyprus/ and that's a fact".

Yet paradoxically, the same self-presentation rejects the essentialising discourses on which these stereotypes of ethnic otherness are based. The complexity and contradictions of being a Turk in London are inherent in the style in which they choose to express their Turkish pride and identity. It is not traditional Turkish folk music, but a rap, a style that originates from black Anglo-American culture. This is further reinforced by the 'hip-hop' style images posted of themselves- a style in which the poses and dress clearly contravene the values of the Turkish diaspora (as they describe them). Thus the 'True Turk' website itself illustrates the 'hybridisation' of Turkish and other identities, even though these young people are reluctant, at best defensive, in verbally acknowledging such hybridisation.

This rap then reflects a means of negotiating an asymmetrical and constraining sociocultural context, and reveals a duality in the ways in which they relate to their identity. The authority of discourses cannot be separated from the actual social positions of self and other (Gillespie, 2005). The Turkish in Turkey have more power to say who is Turkish, and the white English have more power to say who is English, and both seem to reject these second generation immigrants. What emerges is a knotted dialogical identity position that explicitly rejects the English identity while embracing a Turkish identity that they work hard to claim and defend. While the particular context represented by the research setting - being interviewed by a white English woman at their Turkish school - may have foregrounded their I-as-Turkish position, the data also suggests its dominance persists across contexts (e.g. in the wearing of the moon and star pendant or the creation of a 'True Turk' website). 
Yet the dialogical knot remains: they have all been born and brought up in London, schooled in London, are more fluent in English and more "at home” in England. Socialised into this society, they implicitly adopt resources, such as the rap genre, from globalised culture to forge a hybrid identity position that allows them to be competent social actors in the multicultural setting in which they live out their daily lives. However, due to the asymmetries within their sociocultural context, they do so without being able to explicitly claim an English identification.

\section{Adaptive Asymmetries}

How can we understand the constitution of this internally fragmented and asymmetrical dialogical self? Our analysis concurs with Valsiner (2002, p. 259), who argues that different I-positions are distinct "matching psychological devices” for adapting to different social contexts. In some contexts, these young people must deal in the currency of essentialising discourses. In these instances, speaking from I-as-Turkish or I-as-ethnic-other, they suture themselves into the spaces constructed by the identity discourses of more powerful others in their socio-cultural contexts (e.g. parents, the 'white majority'). In other situations, the reifications on which these identifications are based are acknowledged as false, not least amidst the reality of the 'cultural flow and flux' of London. Through a rejection of these discourses in the expression of a more hybridised identity, they are able to undermine these constraining racial chauvinisms, allowing them to build cultural bridges, as, for example, in the diversity of their friendship groups. Thus while reflecting persistent and unresolved dialogical struggles resulting from the asymmetries of power which structure their socio-cultural context, this movement between positions is nonetheless adaptive.

It is now common to assert that identities are multiple, fluid and 'hybridised', reflecting the postmodern condition (e.g., S. Hall, 1996; Bhatia, 2002). In line with this, 
our analysis shows that these young Turks are agentic in appropriating cultural resources to enact a novel and hybridised identity. However, using the concept of the dialogical self, our analysis pushes this line of thought further. Different social contexts and voices - the Turks in Turkey and the white English in England - constrain the field of identity positions that these second generation Turks can occupy, and that constraint reveals itself in the suppression of the hybridised I-position at the level of selfidentifications. Thus by analytically situating the dialogical self within its sociocultural context, one sees beyond the contradictions, to reveal a logical and adaptive response to the hybridity produced by globalisation and the asymmetries of power inherent within it. 


\section{References}

Back, L. (1996). New ethnicities and urban culture: Racisms and multiculture in young lives. London: University College London Press.

Bakhtin, M. M. (1981). The dialogic imagination. Austin: University of Texas Press.

Baumann, G. (1996). Contesting culture: Discourses of identity in multi-ethnic London Cambridge: Cambridge University Press.

Bhatia, S. \& Ram, A. (2001). Locating the dialogical self in the age of transnational migrations, border crossings and diasporas. Culture and Psychology, 7, 297-309.

Bhatia, S. (2002). Acculturation, dialogical voices and the construction of the diasporic self. Theory and Psychology, 12, 55-77.

Da Cunha, M. C. (1995). Children, Politics and Culture: The case of Brazilian Indians. In S.Stephens (ed) Children and the politics of culture. (pp. 282-291) Chichester: Princeton University Press.

Enneli, P., Modood, T. \& Bradley, H. (2005). Young Turks and Kurds: a set of 'invisible' disadvantaged groups. York: Joseph Rowntree Foundation.

Eriskon, E. H. (1968). Identity: Youth and Crisis. New York: Norton.

Gervais, M-C. \& Jovchelovitch, S. (1998). Health and identity: the case of the Chinese community in England. Social Science Information, 37, 709-729.

Giddens, A. (1991). Modernity and self-identity: Self and society in the late modern age. Stanford, CA: Stanford University Press.

Gillespie, A. (2005). Malcolm X and his autobiography: Identity development and selfnarration. Culture and Psychology, 11, 77-88.

Gillespie, A. (2006a). Becoming other: From social interaction to self-reflection. Greenwich, CT: Information Age Publishing, Inc.

Gillespie, A. (2006b). Descartes' demon: A dialogical analysis of 'Meditations on First Philosophy.' Theory \& Psychology, 16, 761-781.

Gillespie, A. (2007). Collapsing Self/Other positions: Identification through differentiation. British Journal of Social Psychology, xxxxxxxx

Gillespie, A., Cornish, F., Aveling, E-L. \& Zittoun, T. (2008). Conflicting community commitments: A dialogical analysis of a British woman's World War II diaries. Journal of Community Psychology, $\mathrm{xxxxxxxx}$

Hall, K. (1995). “There's a time to act English and a time to act Indian”: The politics of identity among British-Sikh teenagers. In S.Stephens (ed) Children and the politics of culture. (pp. 243-644) Chichester: Princeton University Press.

Hall S. (1996). Who needs 'identity'? In Hall S. \& Du Gay, P. (eds) Questions of Cultural Identity. (pp. 1-17) London: Sage. 
Hermans, H. J. M. (1996). Voicing the self: From information processing to dialogical interchange. Psychological Bulletin, 119, 31-50.

Hermans, H. J. M. (2001a). The dialogical self: Towards a theory of personal and cultural positioning. Culture and Psychology 7, 243-281.

Hermans, H. J. M. (2001b). The Construction of a personal position repertoire: Method and Practice. Culture and Psychology 7, 323-365.

Hermans, H. J. M. (2002). The dialogical self as a society of mind. Theory and Psychology 12, $147-160$

Hermans, H. J. M. \& Dimaggio, G. (2007). Self, identity, and globalization in times of uncertainty: A dialogical analysis. General Review of Psychology, 11, 31-61.

Hermans, H. J. M. \& Kempen, H. J. G. (1998). Moving cultures: The perilous problems of cultural dichotomies in a globalising society. American Psychologist 53, 1111-1120.

Hermans, H. J. M., Kempen, H. J. G. \& vanLoon, R. J. P. (1992). The dialogical self: Beyond individualism and rationalism. American Psychologist 4, 23-33.

Howarth, C. (under review). "I hope we don't have to understand racism one day": Problematising racial difference in a British primary school. British Journal of Social Psychology

Howarth, C. (2002). Identity in Whose Eyes? The role of representations in identity construction. Journal for the Theory of Social Behaviour 32, 145-162.

Kvale, S. (1996). InterViews: An introduction to qualitative research interviewing. London: Sage Publications.

James, W. (1890/1981). The Principles of Psychology. Cambridge, MA: Harvard University Press.

Mandel, R. (1995). Second generation non-citizens: Children of the Turkish migrant diaspora in Germany. In S.Stephens (ed) Children and the politics of culture. (pp. 265-281) Chichester: Princeton University Press.

Marshall, C. \& Rossman, G.B. (1995). Designing qualitative research, $2^{\text {nd }}$ edition. London: Sage Publications.

Modood, T., Berthoud, R., Lakey, J., Nazroo, J. Smith, P., Virdee, S. \& Beishon, S. (1997). Ethnic minorities in Britain: Diversity and disadvantage London: Policy Studies Institute.

Nagel J. 1996). American Indian Ethnic Renewal: Red Power and the Resurgence of Identity and Culture. New York: Oxford University Press.

Parker, D. (1995). Through different eyes: The cultural identities of young Chinese people in Britain. Aldershot: Avebury Press.

Rappoport, L. Baumgardner, S. \& Boon, G. (1999). Postmodern culture and the plural self. In J. Rowan and M. Cooper (eds), The Plural Self: Multiplicity in everyday life. London: Sage.

Shotter, J. (1993). Cultural Politics of Everyday Life Buckingham: Open University Press. 
Strauss, A.L. (1987). Qualitative analysis for social scientists Cambridge: Cambridge University Press.

Valsiner, J. (2002). Forms of dialogical relation and semiotic autoregulation within the self. Theory and Psychology, 12, 251-265.

Wertsch, J.V. (1991). Voices of the mind: A sociocultural approach to mediated action London: Harvester-Wheatsheaf. 